\title{
Self Concept In Relation To Participation in National Cadet Corps (NCC) Among Arts and Science College Students under Calicut Uviversity
}

\author{
${ }^{1}$ Divya.T. P., ${ }^{2}$ Dr. K. Rajagopalan \\ ${ }^{1}$ M.Ed.Student,N.S.S.Training College, Ottapalam. ${ }^{2}$ AssociateProfessor, N.S.S.Training College, Ottapalam
}

\begin{abstract}
This study was intended to investigate the relationship between self-concept and participation in NCC among college students. The present study was conducted on a sample of 400 NCC cadets studying in different arts \& science Colleges in Palakkad, Thrissur and Malappuram District by giving due representation to gender (Boys / Girls), locale (Rural / Urban) and type of management of institutions (Government / Aided).Normative survey method was used for collecting the data for the study. The obtained data were analyzed with the help of Pearson's product moment correlation technique. Findings indicate that there exist the chances of those students participating in NCC to have a good self concept are fairly large. The investigator found positive and significant relationship between self concept and participation in NCC for the total sample and for all the subsamples.
\end{abstract}

Key word: Self-concept

\section{Introduction}

The role of education is not only important in the development of culture and society but also in the development of individual's personality. During recent years, changes have occurred in the pattern of culture, society and individual personalities. Education is a process which draws out the best in the child with the aim of producing well balanced personalities - culturally refined, emotionally stable, ethically sound, mentally alert, morally upright, physically strong, socially efficient, spiritually mature, vocationally self-sufficient and internationally liberal.

The personality is composed of traits, or special qualities of behavior, which characterize the individual's unique adjustment to life as shown in his behavior and thought. The traits are organized and integrate into a meaningful pattern. The 'core' or centre of gravity of the personality pattern is the individual's concept of himself / or herself as a person as related to the world in which he lives. The quality of his behavior, expressed in the way he adjusts to people and things in his environment, is related to a large extent by his self concept.

Personality is not a specific quality of a person but a quality of his behavior. How he behaves depends upon how he feels about himself, about other people and about his relationship with them. These feelings makeup his self- concept what he thinks about himself as a person. A person's self - concept is the fundamental love of his entire personality and determines the quality of behavior.

Education should contribute not only to knowledge or information but also to physical efficiency, mental alertness and the development of certain qualities like perseverance, team spirit, leadership, follower ship, obedience to rules, moderation in victory and balance in defeat and the development of self control, endurance, courage, self-concept, comradeship, confidence etc. National Cadet Corps (NCC) gives a good opportunity to develop the above mentioned physical and psychological qualities. NCC is a good platform for the youth to develop their personality.

NCC

National Cadet Corps (NCC) is a Tri service Organization comprising the Army, Navy and Air force, engaged in grooming the youth in to disciplined and patriotic citizens. The National Cadet Corps came in to existence on $16^{\text {th }}$ July 1948 under the NCC Act XXXI of 1948 under the Ministry of Defence

A cadet can continue in NCC for two years as a junior cadet and three years as a senior cadet. Each year of training consists of 150 periods and 120 periods for junior and senior division cadets respectively. Institutional training consists of service subjects, social subjects and subjects related to adventure activities and subjects promoting national integration. During training years, cadets get opportunity to attend various types of NCC camps. At the end of two years training, the cadets can appear for the certificate examinations.

NCC plays a very dominant role in inculcating social ethos in the youth of the country. It undertakes various social service activities like aid to the administration in times of calamities, preservation of environment and ecology, blood donation campaigns, literacy programs and construction and cleanliness drives. NCC trains 
the cadets to become responsive individuals, sensitive to the needs of the community. This active participation teaches dignity of labour and ignites the creative instinct that lies latent in the youth. This is achieved through the scientifically planned NCC curriculum. It aims at developing a new work of ethos characterized by hard work, sincerity of purpose and the ideals of selfless service with a secular outlook.

\title{
Significance of the study
}

Self-concept is the important psychological variable which determines a student's future in his success and progress. The study of self-concept has awakened growing interest in psychological research of recent years. Self-concept has a multidimensional nature. It is considered to comprise various dimensions, areas or facets, some of which are more related to certain personality aspects (physical, emotional, moral, cultural, behavioral), while others appear to be more linked to academic, social interaction, family etc.

The self-concept influences the behavior of adolescents. Adolescent's self - concept and self-esteem are important to their mental health, to their interpersonal competence in social relationship and to their progress in college / school, self-concept and self esteem effect of academic achievement and their aspirations and success. In fact, these concepts affect everything they are, tried to be or do. Self - concept is to be improved positively with a view to responding in himself confidence, which in turn acts as an impetus for the all round development of his personality.

To be successful in life, one has to be bold to take calculated risk even at great discomfort. NCC develops these qualities in youth by putting them through rigorous training including adventure activities (which include : mountaineering and trekking expeditions, rock climbing, Para training and jumping camps, gliding, slithering, micro light flying, sailing, surfing, scuba diving, boat pulling etc.) NCC trains the cadets to become responsive individuals, sensitive to the needs of the community. It develops mutual respect, adaptability, self discipline, cross cultural learning, self - confidence and above all, love for one's country. A major need of NCC is to develop character, comradeship, discipline, leadership, secular outlook, spirit of adventure and ideals of selfless service amongst the youth of the country. NCC aims at development of the whole man. Performance in NCC should help the individual to realize his potentials.

\author{
Variables \\ Self Concept - Dependent variable \\ Participation in N.C.C - Independent variable \\ Classificatory variables \\ a. Gender \\ b. Locale \\ c. Type of management of institution.
}

\section{Objectives}

1. To find out the relationship between self concept and participation in National Cadet Corps among college students for the total sample and relevant sub samples Gender, Locale and Type of management of institutions

2. To find out whether there exist a significant difference in the relationship between self concept and participation in N.C.C for the relevant subsamples Gender, Locale and Type of management of institutions

\section{Hypotheses}

1. There exist significant relationship between self concept and participation in N.C.C among college students for the total sample and relevant subsamples Gender, Locale and Type of management of institutions

2. There exist significant difference in the relationship between self concept and participation in N.C.C for the relevant subsamples

Normative survey method is used for the study.

\section{Method}

\section{Sample}

Sample selected for the study consists of 400 N.C.C students of arts \& science colleges under University of Calicut.

\section{Tools}

The investigator used the following tools to measure the variable

1. Self-concept Scale Constructed and standardized by Dr. K.Rajagopalan and Meera.T. (2011). 
2. Questionnaire to find the extent of Participation in NCC (Constructed and standardized by the investigator with the help of supervising teacher).

\section{Results and Discussion}

The following results were obtained from the study.

a. There exist significant, moderate relationship between self concept and participation in NCC for the total sample. The correlation between the two variables is found to be 0.69 . The critical ratio obtained for the total sample is found to be 19.34 which is significant at 0.01 level.

b. There exists significant, high relationship between self concept and participation in NCC for the subsample of boys. The correlation between the two variables is found to be 0.71 . The critical ratio obtained for the subsample is found to be14.29 which is significant at 0.01 level.

c. There exists significant, moderate relationship between self concept and participation in NCC for the subsample of girls. The correlation between the two variables is found to be 0.68 . The critical ratio obtained for the subsample is found to be12.99 which is significant at 0.01 level.

d. There exists significant, moderate relationship between self concept and participation in NCC for the subsample of students of rural colleges. The correlation between the two variables is found to be 0.69 . The critical ratio obtained for the subsample is found to be13.18 which is significant at 0.01 level.

e. There exists significant, high relationship between self concept and participation in NCC for the subsample of students of urban colleges. The correlation between the two variables is found to be 0.70 . The critical ratio obtained for the subsample is found to be 14.15 which is significant at 0.01 level.

f. There exists significant, moderate relationship between self concept and participation in NCC for the subsample of students of aided colleges. The correlation between the two variables is found to be 0.66 . The critical ratio obtained for the subsample is found to be 12.98 which is significant at 0.01 level.

g. There exists significant, high relationship between self concept and participation in NCC for the subsample of students of government colleges. The correlation between the two variables is found to be 0.74 . The critical ratio obtained for the subsample is found to be 14.50 which is significant at 0.01 level.

Table 1 Details of relationship between Self Concept and Participation in NCC

\begin{tabular}{|l|l|l|l|}
\hline Sample & N & r & Critical ratio \\
\hline Total Sample & 400 & $0.69^{* *}$ & 19.34 \\
\hline Boys & 204 & $0.71^{* *}$ & 14.29 \\
\hline Girls & 196 & $0.68^{* *}$ & 12.99 \\
\hline Rural & 193 & $0.69^{* *}$ & 13.18 \\
\hline Urban & 207 & $0.70^{* *}$ & 14.15 \\
\hline Aided & 219 & $0.66^{* *}$ & 12.98 \\
\hline Govt. & 181 & $0.74^{* *}$ & 14.50 \\
\hline
\end{tabular}

** Correlation is significant at the 0.01 level

2. When difference between $r$ 's was tested for significance the following results were obtained.

a. There does not exist significant difference in relationship between self concept and participation in NCC among college students for subsamples based on gender. The critical ratio obtained is 0.59 which is not significant at 0.05 level.

b. There does not exist significant difference in relationship between self concept and participation in NCC among college students for subsamples based on locale. The critical ratio obtained is 0.19 which is not significant at 0.05 level.

c. There does not exist significant difference in relationship between self concept and participation in NCC among college students for subsamples based on type of management. The critical ratio obtained is 1.58 which is not significant at 0.05 level.

Table 2 Results of test of significance of difference in r's between self concept and participation in NCC

\begin{tabular}{|c|c|c|c|c|}
\hline Sl. No. & Sample & $\mathbf{N}$ & $\mathbf{r}$ & Critical Ratio \\
\hline 1 & Boys & 204 & $0.70 * *$ & \multirow{2}{*}{0.59} \\
\hline 2 & Girls & 196 & $0.68 * *$ & \\
\hline 3 & Urban & 207 & $0.70 * *$ & \multirow{2}{*}{0.19} \\
\hline 4 & Rural & 193 & $0.69 * *$ & \\
\hline 5 & Government & 181 & $0.74 * *$ & \multirow{2}{*}{1.58} \\
\hline 6 & Aided & 219 & $0.66 * *$ & \\
\hline
\end{tabular}

\section{Educational Implications}

The result of the present study revealed that participation in NCC played a dominant role in developing self concept of college students. In the emerging new trends in the field of education the need for developing proper self concept among college students is of prime importance. 
Some of the educational implications of this study are the following.

1. College authorities can create suitable environment to motivate the students to participate in NCC, for developing self concept, qualities of character, courage, comradeship, discipline, leadership, secular outlook, spirit of adventure and sportsmanship and the ideas of selfless service to make them useful citizens.

2. Provide guidelines on the importance of NCC to the students in order to recognize its social significance.

3. Assure student participation in NCC as it is very effective to develop self concept and democratic values.

4. It will be fruitful to the adolescents if all the schools and colleges are establishing NCC units.

5. Central government should support unaided schools and colleges to start NCC units.

6. Make sure the availability of NCC officers in all schools and colleges, so that they can arrange classes, camps and the activities of NCC for the cadets.

7. Make sure the active participation of girls to improve their self concept and prepare them for self defense.

\section{References}

[1]. Best. J.W. and Kahn J V (2005) Research in education, New Delhi: Peason Education Pvt. Ltd.

[2]. Buch, M.B. (1987). Third survey of research in education. New Delhi: NCERT.

[3]. Garett, H. E. (1981).Statistics in Psychology and Education. New Delhi: Paragon International Publishers.

[4]. Guilford, J.P. \& Fuchter, B. (1978). Fundamental statistics in psychology and education. Tokyo: Mc Graw-Hill.

[5]. Koul Lokesh. (2010). Methodology of Educational Research (Fourth Revised Edition). New Delhi: Vikas Publishing house Pvt. Ltd.

[6]. Rogers, C.R. (1951). Client Centered Therapy. New York: Houghton Mifflin.

[7]. Rogers, C.R. (1959). A theory of therapy: Personality and International relationship as developed in the Client centered frame work. In C.S. Hall and G. Lindzy, Theories of Personality, U.S.A, John Wiley and Sons.

[8]. www.Keralancc.org

[9]. www.psgtech.edu/ncc/02NCC info.html

[10]. nccindia.nic.in/

[11]. en.wikipedia.org/wiki/National Cadet Corps india

[12]. www.delhigov.in/wps/wcm/connect/DOIT_NCC 